\title{
Distinguishing Practical and Theoretical Reasoning: $A$ Critique of Deanna Kuhn's Theory of Informal Argument ${ }^{1}$
}

\author{
MatrHeW Wilks KeEfer, University of Missouri - St Louis
}

Keywords: Argumentation, Informal Reasoning, Practical Reasoning, Theoretical Reasoning

\begin{abstract}
Deanna Kuhn's theory of informal argumentation (1991) evaluates arguments according to a theory/evidence model where subjects first articulate a theory and then must provide critical testing of alternatives on the basis of evidence. Using this model, Kuhn reports that many subjects fail to supply adequate evidence for their 'theories' and are often unable or unwilling to generate alternatives. In this paper an account of practical reasoning is provided that suggests an alternate interpretation for Kuhn's subjects' poor performance. It is argued that treating practical arguments as failed theoretical justifications causes Kuhn to misrepresent the contribution of many of her subjects' arguments.
\end{abstract}

Résumé: La théorie d'argumentation informelle formulée par Deanna Kuhn évalue des argumentations selon un modèle théorie/ démonstration dans lequel des sujets expriment une théorie et, ensuite, doivent critiquer cette théorie en s'appuyant sur une démonstration. Ayant eu recours à ce modèle, Kuhn remarque que plusieurs sujets négligent de démontrer adéquatement leurs théories et sont souvent incapables ou peu disposés à inventer des contreparties. Cet article propose une description du raisonnement pratique qui suggère une autre interprétation de la performance décevante des sujets de Kuhn. On soutient que Kuhn fausse l'image des argumentations de ses sujets parce qu ${ }^{x}$ elle traite les argumentations pratiques comme des justifications théoriques ratées.

\section{Introduction: Understanding informal argument.}

Deanna Kuhn asks the important question: "To what extent does a process of rational argument in fact underlie the beliefs people hold and the judgments and decisions they make?" (Kuhn, 1991, p. 3) The question is important to Kuhn as she believes that "thinking as argument is implicated in all the beliefs people hold, the judgments they make, and the conclusions that they come to. It arises every time a significant decision must be made. Hence, it is at the heart of what we should be interested in and concerned about in examining people's thinking" (Kuhn, 1991, p. 2).

The argument behind Kuhn's understanding of "thinking as argument" is that our beliefs are chosen from among alternatives on the basis of the evidence for them. Her research program puts into question and tests the extent to which individuals actually do hold their beliefs on the basis of evidence. While we as a society, Kuhn argues, spend much of our time and effort determining what it is that we believe, we know and seem to care little about how it is we come to believe what we do. Kuhn asks:

Do people know why they believe what they do, in a way that they can justify to themselves and others? Do they even know what they believe, in the sense of being 


\section{Matthew Wilks Keefer}

consciously aware of these beliefs as choices they have made among many different beliefs they might hold? Do they understand what sort of evidence would indicate that a belief should be modified or abandoned? (Kuhn, 1991, p. 3 [emphasis in original])

The answer that Kuhn provides to this question is rather disturbing as many people, it seems, do not or cannot give adequate evidence for the beliefs they hold. Furthermore, many of these same individuals seem unwilling or unable to consider revising their beliefs when presented with the possibility of evidence against them. Kuhn holds that reasoned argument requires, at its base, just this ability to distinguish theory and evidence. Subjects who fail to achieve this variety of critical purchase, Kuhn argues, cannot claim to be fully in control of the beliefs and knowledge they possess. And, Kuhn warns us, "To know and be in control of what they think may be the most important way in which people can hope to control their lives, both individually and collectively as a society" (Kuhn, 1991, p. 3).

Kuhn arrived at the evidence for her own beliefs by asking her experimental subjects what they think is the major cause of an important social problem. For example, she asks subjects to decide on the cause underlying the fact that many prisoners return to prison or why it is that children fail at school. Subjects must then justify their account or "theory". Specifically, they are asked: "If you were trying to convince someone that your view is right, what evidence would you give to try to show this?" Finally, Kuhn requires her subjects to address counter positions by giving them the task of envisaging how someone could show or prove that their theory is wrong.

The problem with all this, it will be argued below, is that being "in control" of what we believe is not achieved only in the manner that Kuhn describes. That is, many of the values and beliefs that form and inform what we decide to do (and how we defend what we do) are not chosen from among alternatives in the way that Kuhn imagines, i.e., on the basis of the "evidence" for them. The reason that Kuhn is able to suggest otherwise is that her approach (derived as it is from argumentation in natural science) is designed to treat individuals' general accounts of important social phenomena as social scientific hypotheses. In doing so, légitimate forms of practical argument are inappropriately subsumed under a scientific model of informal reasoning.

It should be said at the outset that Kuhn should be commended for tackling the difficult job of trying to make sense of our practices of informal argument. She should also be praised for a serious commitment to testing her ideas, as well as for the boldness of her formulations. Pioneering work in the area of informal reasoning presents considerable obstacles for any researcher, and we should be aware of the early stage of this research. The criticisms that follow pertain only to a limitation that is perceived to be endemic to the framework that guides Kuhn's research program. That is, this critique is aimed mainly at what Kuhn may have missed, and not with the adequacy of the mature forms of reasoning that she identifies and promotes.

The problem that Kuhn encounters is that the criteria for judging a practical argument differ markedly from those used to judge the validity of a scientific hypothesis. For example, a theory ought have empirical consequences and those consequences must be subjected to test by public procedure; procedures that can provide a kind of rational court of appeal. Kuhn's view of having good reasons for one's beliefs seems 
to conform closely to this empirical/scientific model. Exemplary forms of her subjects' reason-giving (what she calls providing "genuine evidence") display many of just these characteristics. Consider these subjects' accounts of recidivism and school failure.

[family problems] Well, if someone makes a study of cases of students where failures, dropouts .. students who drop out of school ... and sees where they have family problems, perhaps that would be solid evidence to prove what I mean.

[unemployment] You could probably could probably take a survey and find out the percentage of people who get jobs who have been convicts. I'm sure it is very low.

[drugs] I guess people who have drugs and might not be doing so great in school, and so if they knew they took drugs they could see what happened when they weren't on drugs and, you know, prove it or whatever. (Kuhn 1992, p. 160)

What these responses have in common is that they are attempts to apply basic principles of experimental science, i.e., the manipulation and control of variables in order to isolate relevant antecedents. Assessing a good theoretical argument (in Kuhn's task a good theory) requires an evaluation of whether the interlocutor has correctly determined the kind of evidence that would be necessary to support it (and counterfactually, the evidence that would falsify it). But, assuming the evidence can or will be corroborated, there may be little need of justification in any substantive or practical sense. If evidence did not corroborate the theory, the hypothesis-as-stated would need to be revised (if not abandoned). ${ }^{2}$ Theoretical reasoning, then, does not directly address the question of whether the hypothesis gives a good practical or substantive account of the phenomenon under discussion.

If assertions are to be characterized as susceptible to disagreement in this way, the question can be raised whether Kuhn's normative model can accommodate the variety of ways in which we justify our informal knowledge and beliefs. For instance, some theorists would argue that justification and argument are at issue only when there exists the possibility of substantive disagreement.

The problem of justification arises only in the practical realm, when it is a question of decision, an action, or a choice that has no incontrovertible evidence to guarantee its validity.... The enterprise of justification has meaning only if the acts one is seeking to justify are open to criticism; that is, if they possess some fault that makes them inferior to other acts which are uncriticized and therefore need no justification.

(Perelman, 1980, p. 59)

It may be that Kuhn's model provides an inadequate account of argumentation in the practical realm; i.e., that realm where we try to give the best account of why a particular (class of) person(s) choose to behave as they do. A problem occurs in that our practical and theoretical judgments have different starting points as well as different goals and purposes. For example, in our practical discourse there is not any sure method or procedure by which we can judge whether something is rationally justified a priori. Rather, it is the basic premises or "commonplaces" of our practical thought that provide the point of departure from which we can attempt "to justify, through controversy, the best, the most reasonable opinion" (Perelman, 1980, p. 100). The notion of controversy is different in the two instances as well. In practical argument the starting point is reputable opinion and the goal, justified belief; whereas, in theo- 


\section{Matthew Wilks Keefer}

retical reasoning a claim is judged by appeal to the evidence that supports it. And genuine evidence, as Kuhn defines it "is, by no means, evidence that is conclusive, nor even compelling, nor even necessarily very convincing evidence. Rather, it is simply evidence that is (a) differentiated from the theory... and (b) bears on its correctness" (Kuhn, 1993, p. 78). A theory or claim may (in this way) receive confirmation and yet not be considered, ceteris paribus, the best or even a very suitable explanation from a practical viewpoint.

It will argued that it is just this failure to treat their arguments as theories that is the reason many of Kuhn's subjects misunderstand and hence "botch" the requirement to distinguish theory from evidence. The question is whether this perceived lack of competence might be due to a failure on Kuhn's part, in particular, a failure to distinguish procedures that constitute the refutation of a scientific hypothesis from considerations relevant to a substantive disagreement in a practical argument. In order to make this argument it is first necessary to clearly distinguish practical from theoretical reason. This distinction will then provide a basis for an alternate account of practical reasoning and argument, i.e., an alternate account of how we come to have and to hold the beliefs that underlie our practical knowledge and opinions. This framework will then be applied to help explain the poor performance of subjects reported in Kuhn's studies.

\section{Part I : Distinguishing practical and theoretical knowledge.}

The kind of knowledge that Kuhn's line of questioning tries to elicit from her subjects is theoretical or scientific knowledge. A basic strategy in scientific reasoning is to explain an action sequence or event by finding another which caused it. Here, knowledge of the event or outcome may be derived from knowledge of its antecedents or correlates. $^{3}$ Explanation might then provide for the prediction of future occurrences (given similar conditions) as well as opportunity for manipulation and control. Theoretical knowledge addresses such questions as, "What is the underlying cause of this event?" or, "Does A vary reliably with B in situations of type Y?" It is knowledge that conforms with an independent external reality (Hollis, 1994). There is an important sense in which the knowledge or object of inquiry is independent of the agent of the inquiry, and awaits only the identification of the relevant statistical association or, discovery of the appropriate cause-effect sequence.

In contrast, many have argued that the explanation of human action cannot be accomplished by focusing solely on such methods (Robinson, 1985; Hollis, 1989, 1994; Taylor, 1964; von Wright, 1971). These authors maintain that the agent's own understanding of their reasons should be included as part of any comprehensive account. Yet, human actions are radically underdetermined by their "reasons" and cannot be derived from reasons in any strict sense. Moreover, the knowledge that informs our practical reasoning is concerned not primarily with what is, but with what it is one can (or should) do. It is the form of knowledge that encounters the realm of human possibilities, the ethical domain of human values.

In coming to know theoretically, one comes into accord with prior reality. But in coming to know practically, one becomes able to bring something into reality. It 
follows that practical knowledge cannot have its truth by conformity to what is known. Rather, a practical proposition is true by anticipating the realization of that which is possible through acting in accord with that proposition, and by directing one's action toward that realization. (Grisez, Boyle \& Finnis, 1987, pp. 116-17)

This is not to say that our practical knowledge and beliefs are somehow exempt from claims to truth or consonance with reality, though it will be argued that the relation between the truth of one's belief in the value of a practical proposition, and its actual value, may not be so easily separable (see Hollis, 1994; Raz, 1986).

Perhaps most important for our purposes is the claim that there are different kinds of considerations that direct us in our pursuit of these different forms of knowledge. Much of our practical thinking exhibits apparent agent relative characteristics. People invariably show a partiality to their own pursuits and projects and are likely to weight the importance of the reasons for their own goals disproportionately in relation to those of others. Understanding this important aspect of practical thinking is made easier if we distinguish the different kinds of reasons agents have for their actions. The analysis I will follow here is taken from Raz (1986) (see also Parfit, 1984). The example frequently given is that parents have reason that their children be cared for. That is, they have reason that the nourishment, health, and educational needs of their children are met so that their children will develop aright and (perhaps) even flourish. These are outcome reasons. They are reasons that support a certain event or outcome taking place. However, parents also have reason to care for their own children. Part of what it means to be a parent (to experience the value of parenting) is to actively partake in the upbringing of one's own children. These are action reasons. Action reasons are considerations that pertain usually to certain classes of agents and are centrally concerned with what they do and not simply with what happens or occurs. They are reasons that "are based on the value of a particular (class of) agent(s) performing a certain action..." (Raz, 1986, p. 145), and so apply (only) when the value of the goal is dependent on the agent having performed the actions and not just their having occurred. So, action reasons can be usefully contrasted with reasons that support a certain event or outcome taking place and may be either agent relative or agent neutral.

Table 1

Action and outcome reasons

\begin{tabular}{|c|c|c|}
\hline & Action Reasons & Outcome Reasons \\
\hline Agent Relattve & $\begin{array}{c}\text { I should care for my } \\
\text { own children }\end{array}$ & $\begin{array}{c}\text { My children should } \\
\text { have enough for their } \\
\text { needs }\end{array}$ \\
\hline AGent Neutral & $\begin{array}{c}\text { Children should be } \\
\text { cared for by their } \\
\text { parents }\end{array}$ & $\begin{array}{c}\text { Children should have } \\
\text { enough for their needs }\end{array}$ \\
\hline
\end{tabular}


Action reasons have an important function in our practical thinking. According to Raz, a person's values and pursuits "provide him with action reasons [and] are constituted and endorsed by action reasons" (Raz, 1986, p. 306). The goals and values that are the object of our active pursuit are available to the agent only through a commitment over time to the practical reasoning that is constitutive of them. Our significant goals and beliefs are held for reasons. These practical (agent neutral) reasons pertain more to the value of the goal than the desire or will of the agent. It appears, then, that agents may have reason to be partial to the (practical) reasons that direct them in their own pursuits and projects; a partiality that should not be interpreted as purely selfinterested or uncritical.

To summarize: our practical knowledge is the knowledge that is inherent in the experience of bringing something to fruition. The reality it "knows" is available by and through the agent's "doing" as it pertains to the active pursuit of that value or project. The locus of the knowledge that allows for this possibility resides not in the world but in the agent's actualization of certain commitments by honoring and effecting the appropriate considerations. The reality it "knows" it knows (partially) because it has brought it into being, or, if you prefer, it is the nature of this kind of knowing that its being brought into reality is constitutive of it. The claim is that an agent may manifest a partiality for the reasons that support certain values and goals that does not signal a failure to assume a critical stance in relation to them. It is to the defense of this claim that we now turn.

\section{The difficulty of knowing the reasons that support our practical knowledge and beliefs}

Partly as a consequence of the way they are acquired, our practical knowledge and beliefs and the reasons for holding them do not attain the same degree of independence or transparency as do theoretical beliefs, i.e., beliefs-stated-as-a-hypotheses. There are several reasons for this. First, there is the issue of falsifiability. Since the knowledge and reasoning that guides us in the pursuit of value is practical, (i.e., the knowledge of bringing something into reality), it follows that we do not or cannot know beforehand what a commitment to a basic value or goal will bring about in advance of our acting in accord with it. So, the knowledge that supports our basic values and beliefs differs from theoretical beliefs in that it is open-ended. There is often not any single point in time where we might say that our goal has been met or the value secured. ${ }^{4}$ In contrast, an important quality of theoretical beliefs is that they remain open to refutation, and that requires as clear a demarcation as possible between hypothesis and empirical consequences. But perhaps the most significant barrier to transparent knowledge of the reasons that support basic values and commitments relates to the pervasive incommensurability of human values. Yet such incommensurability should not just be understood only as a shortcoming or a limit to the clarity of our informal reasoning. On the contrary, following Raz, it will be argued that knowledge of incommensurability is also constitutive of our understanding of basic goals and commitments. 


\section{Practical choice and the incommensurability of value}

The reality of incommensurability can be comprehended only when one considers the complexity of human choices. Important decisions usually involve a choice between comprehensive goals or values. The term "comprehensive" relates, roughly, to the pervasiveness of a goal in regard to the overall life plans and projects of the agent. The more pervasive or comprehensive the goal, the more likely it is to be embedded or implicated in hierarchical nested structures. ${ }^{5}$ Our significant choices are usually made between goals that are embedded in these hierarchical nested structures. ${ }^{6}$ As these structures support values constituted by action reasons, the problem for practical choice is complex indeed. Not only are there many different ways to pursue a single comprehensive goal; there are also many different comprehensive goals and values to be pursued. Realistically, this means that given any situation of significant choice, the agent will likely be committed to reasons for pursuing more than one goal (see Walton, 1990).

It has been argued that, in the practical sphere, agents do not have available a transparent knowledge of the reasons for engaging in valuable pursuits. However, while it is neither necessary nor possible to know all the reasons why one believes in or pursues a basic goal, it is often necessary to know the reasons that one cannot believe in or act on when holding to that goal or project. This is to claim that the successful pursuit of a basic goal or values requires knowing what one cannot trade for it. To make the judgment (say) that friendship is infinitely more valuable than money is not to say that friendship so clearly outweighs the value of money (or has infinite weight) that there really is no comparison. Rather, to make a judgment of incommensurability is simply to claim that the reasons for and against either option cannot be compared, even in principle. This is not to suggest that in such cases we do not really choose, nor is it to deny that we are capable of making reasoned choices. "Statements of incommensurability", writes Raz, "... do not compare the value of the options. They are denials that the values are comparable" (Raz, 1986, p. 329). They constitute a denial that there is any notion of value independent of the actual choice for one or the other option.

The significance of this aspect of our practical knowledge is that it limits the role of comparison in the assessment of values and choices. This is an essential, yet often neglected component of practical thinking. One major reason for its neglect is that such reasoned judgments of incommensurability, as Raz notes, are often mistaken as a sign of comparability.

Certain judgments about the non-comparability of certain options and certain attitudes to the exchangeability of options are constitutive of relations with friends, spouses, parents, etc. Only those who hold the view that friendship is neither better nor worse than money or other commodities are capable of having friends. This is a reasoned attitude. ... Since it is a reasoned preference for one option over another it looks like a ranking, like judging friendship to be more valuable than money. (Raz, 1986, p. 352 [emphasis in original])

For Raz, the reality of incommensurability should not be understood only as a shortcoming or limit to the clarity of our informal reasoning. Knowledge of incommensurability is also constitutive of our understanding of basic goals and commit- 


\section{Matthew Wilks Keefer}

ments. To actively choose according to the meaning of the value, and to know how to defend one's choice, is part of what it means to be a person committed to that value or pursuit. A consequence of these practical judgments, and this will be important later on, ${ }^{7}$ is that "belief in their existence contributes to an attitude which is a barrier to exchange." The barrier may be perceived as so immutable that, depending on the nature of the commitment, the agent may experience "the very thought that they may be comparable in value as abhorrent" ( $R a z, 1986,346$ ). Raz refers to such a choice (based on an incommensurable judgment) as a symbolic action, that is, an action that "illuminates, for those who understand it, the nature of the choices they face in matters far beyond that action itself... " (Raz, 1986, p. 350). An important characteristic of these reasoned judgments of incommensurability (considerations that we shall see are used in the justification of practical arguments) is that they support assessments and choices that express our most cherished values and commitments.

\section{Practical knowledge and our practice of giving reasons}

These same considerations that guide us in our choice of actions and values do not determine or force us to act in any determinate manner. Rather, they offer a justification for acting as we did, as well as illustrate the value we accord to such considerations by the fact that we choose to act in accordance with them (Johnston, 1989; Harré, 1984; Milligan, 1980). It is in this way that they help constitute the norms that direct and inform our practical rationality. As practical norms they pertain primarily not to what is but to what is to be.

In making a decision about what is to count as a reason for him, the agent is not deciding about what is the case, but about what is to be the case. It is not like deciding about a matter of fact,... Rather it is through his decision that it is a reason for him. In making that decision he is evaluating and committing himself to a particular evaluation. (Milligan, 1980, p. 75)

The reasons that support our practical decisions, like the actions themselves, are chosen and not just discovered or established on the basis of evidence. This is not to say that the belief-premises of our practical knowledge are somehow above criticism nor need have any connection with reality. Defending the expressive nature of practical rationality does not entail a commitment to what Charles Taylor calls a "vulgar Wittgensteinian" position (see Taylor, 1981). That is, it doesn't entail that what is valuable to people somehow reduces to what they decide is worth acting on. Value can still be understood as residing in the objective value of the goal or pursuit (available in this particular polis) and not simply "constructed" without constraint by the individual (or collective) exercise of this faculty of practical reason and choice (see also Raz, 1986 , pp 310ff). Rather, it is to emphasize that in the everyday world these practical considerations pertain more to agents than to the explanation of processes or events understood in any disinterested sense. (Robinson, 1985)

Human beings are well aware of the practical knowledge and integrity that is wrought by commitment to significant life choices. They are aware that their commitment to certain forms of action (that are in line with certain values etc.,) make and mark them as more or less competent in that value or practice. The practical knowledge that guides them in their daily decisions and choices, in turn provides them with 
(deeper) knowledge of the meaning and significance of these values and pursuits. Well educated and not-so-well educated alike can, by choosing their goals and values, choose to be the kind of people they are (or the people they are to become) by the exercise of this faculty. This can include (and this will be important later) choosing this very value of autonomy and self-determination by affirming the unique contribution of one's own practical knowledge.

For human nature also includes the capacities of practical knowledge and free choice, and these not only enable a person to realize possibilities which are defined independently of their exercise, but to define and project possibilities in and through their exercise. Thus not only the actualization of the possibilities of human fulfillment but those very possibilities themselves partly depend upon human persons' practical knowledge, free choices, carrying out of these choices, and the results of carrying them out. (Grisez, Boyle \& Finnis, 1987, pp. 116-17).

\section{Our practical knowledge and beliefs: Some conclusions}

The theory of practical reasoning sketched out above suggests that a good deal of our knowledge of significant goals and beliefs needs to be understood practically, as reasons for choice and action. Furthermore, the valuation of our practical beliefs and the "evidence" in support of them do not attain the degree of logical independence that obtains between scientific hypotheses and their evidential confirmation.

Why? Several reasons have been suggested. First, there is the incapacity of human beings to actually know (or have available) all the reasons for believing in or pursuing a significant goal or value. Other concerns addressed the dialectical reality of self-determination, as well as the open-ended character of values and goals. Added to this was the argument that the incommensurability of different spheres of value constitutes a conceptual obstacle to the comparative evaluation of comprehensive goals and values. Critical testing by alternatives requires comparison according to some "criteria" and the incommensurability of value spheres makes this difficult. Furthermore, given that the determination of an agent's (various) identities and social roles are often closely bound up with the values or pursuits at issue, it is not unlikely that as subject of the decision, the agent may be so implicated in the choice that it will be difficult to discern what will be best for whom. Yet the difficulties stemming from incommensurability should not be understood only as an obstacle to the clarity of our practical beliefs. Reasoned judgments of incommensurability also allow us to express our commitment to cherished values and pursuits, thus enabling us to continue to participate in their meaning and to appreciate their significance.

We are now in a position to appreciate the importance of our informal beliefs and opinions as expressions of our practical knowledge and values. They are what we use to get around with in our everyday life, i.e., what we apply to the negotiation of our significant choices and valuable pursuits. It is here where the view of practical thinking based on the comparability of options and claims (on the basis of evidence) perhaps most distorts the nature of our informal thinking. The trouble with such views, according to Raz, is that they assume "that valuing an option is one thing and believing that one does is another and is logically independent of one's valuation." Whereas, with the reasons for our basic values and beliefs "the two tend to merge (thought not to 


\section{Matthew Wilks Keefer}

a degree which makes self-deception or mistakes about one's own beliefs impossible)" (Raz, 1986, p. 351).

\section{Part II: A critique of Deanna Kuhn's theory of informal argument}

\section{Defending practical arguments}

The account given above can be extended to provide an alternate understanding our informal explanations of human action as well as their defense. For instance, since practical knowledge provides the opportunity to define and project possibilities for persons in and through its exercise, one way to articulate the meaning of an important value or pursuit is to narrate the transition to it. As Charles Taylor observes "[p]ractical reason... is a reasoning in transitions" (Taylor, 1989, p. 72). "It aims to establish, not that some position is correct absolutely, but rather that some position is superior to some other." This suggests that the criteria for defending practical arguments may be different. "We can show one of these comparative claims to be well founded when we can show that the move form $A$ to $B$ constitutes a gain epistemically... The argument fixes on the nature of the transition from A to B" (Taylor, 1989, p. 72 [emphasis in original]). The force of this kind of argument relates to the verisimilitude of the transition, the coming into knowledge or actualization of practical knowing. The kind of reasoning adequate to this task is not reasoning of the impartial character that Kuhn describes. Rather, Taylor believes that " $[\mathrm{t}] \mathrm{his}$ form of argument has its source in biographical narrative" (Taylor, 1989, p. 72). ${ }^{8}$ It is the narrative itself that provides the connection between one's reasons and the action or behavior to be explained. It's role is precisely to supply the context wherein the action or value can be understood as intelligibly chosen. Practical or transition type arguments are in this sense rhetorical (Aristotle, 1992). Their function is to persuade not to prove. They try to articulate just how persons have come to hold the values they do in a way that can render intelligible why they choose to act in accord with them (MacIntyre, 1984).

Taylor's analysis of a practical or transition argument is helpful in understanding why many of Kuhn's subjects resist admitting that their arguments can be wrong. Put bluntly, to contradict my practical argument can be interpreted as a negation of the transitions constitutive of my practical knowledge (and perhaps, identity). The important thing to remember about such arguments is that the narrated transition is itself evidence for the claim, i.e., the rhetorical force of the argument is constituted by the narration. The narration is not the defense of a claim but rather constitutes, or is an expression of, the claim.

Contra Kuhn, Taylor's reflections suggest that holding to a practical or transition argument does not mean that one has failed to attain a critical purchase on one's own practical knowledge, nor does it prejudice one's openness to experiencing the force of other transition arguments. This suggests that the criteria for refutation may be more complicated than Kuhn imagines. What would be required is not only that the alternative transition argument embody elements not included in one's own, but that its narration precludes the very possibility of one's own. They would have to be mutually exclusive. If they were not, or were perceived as though they were not, one legitimate 
strategy would be to try to assimilate the alternate account into one's original descriptive framework, i.e., to incorporate them as different aspects of the same general story. This is, it appears, just how some of Kuhn's subjects handled the requirement that they generate alternative accounts. Kuhn reports that some of her subjects,

offered what appeared to be an alternative, but then immediately agreed with it "That could be a part of it too" - in effect incorporating the alternative cause into their own theory. They did not conceive of anything that was not a cause. Other subjects tried unsuccessfully to generate an alternative and instead produced something very similar to their own theory. (Kuhn, 1992, p. 163 [emphasis in original])

In his supportive review of Kuhn's book The Skills of Argument, Jonathan Baron (1991) suggests that a potential difficulty with Kuhn's method is that it forces her to assume that all of her subjects actually do hold a position on the issues under discussion. Baron then worries whether subjects who agree with the alternate theories that they themselves generate do so simply out of an acknowledged ignorance, i.e., an acknowledgment that they simply do not have a view one way or the other. Baron dismisses the problem of ignorance by suggesting that there is evidence most "subjects had in fact thought about these questions before they were interviewed and had formed clear views that they had held with confidence" (Baron, 1991, p. 64).9 The problem of agreement with alternate theories is then explained by the observation that, as noted, most subjects were certain they had a view and, anyhow, many "[s]ubjects who generated multiple theories initially were in fact more successful than other subjects in generating an alternative that they did not accept" (Baron, 1991, p. 64).

The argument here is that these subjects are presenting different kinds of arguments with different structures, not that they fail to actually have a opinion. In a practical or narrative type argument the aim is to provide a context wherein that action or behavior may be understood as rationally willed or intelligibly chosen. When one is faced with the task of giving another account of how the behavior might be chosen, there is little reason to perceive the request as requiring an entirely new context; one that would must preempt or contradict the one previously articulated. Rather, the new narrative may be included "as part of it too" in precisely the sense of widening the scope of a general account of how that class of persons (e.g., school failures or recidivists etc.) end up acting as they do. Responses such as these suggest that many of Kuhn's subjects may "unsuccessfully" generate alternatives for the simple reason that they are not treating their account as falsifiable in the manner of scientific or empirical hypotheses.

\section{The falsification of practical arguments}

What would be necessary to show that one's practical argument is wrong? Perhaps what is needed is some alternative transition type argument powerful enough to persuade one that one's own view is limited or only a part of this more comprehensive view. But one must be shown to be wrong, and this suggests once again that accepting or dismissing a practical argument involves negotiation of qualitatively different criteria. Practical or transition arguments must move one, not (just) by the logic of the reasoning but by experience of the transition. It is perhaps not surprising that many of Kuhn's subjects simply balk at trying to specify what others might say to show their 
"theory" wrong.

But most interesting were the subjects who declined, for example:

I don't know what someone else would say, I have no idea.

I don't know what they would say. I'd really have to get someone else's point of view. 'Cause I imagine my thoughts run in this direction and that's about it. (Kuhn, 1992 pp. 163-64)

It could be argued that to expect subjects to generate an alternate argument bearing these characteristics on the spot is unreasonable. The argument here is just the milder one that a failure to do so may have nothing to do with a failure to distinguish theory from evidence in their informal thinking. As previously noted, practical knowledge of a phenomenon is attained only when one has come to know the phenomenon (including the evidence for it) in a certain light. It follows that if "counter evidence" or new practical experience were to supplant one's own view, then one's own view would now become a different view. One is no longer related to the phenomenon as one was. One now "knows" or "sees" it differently. Assuming this form of argument is the one that these subjects are defending, a perfectly reasonable response might be:

"If I knew the evidence that I am wrong, I wouldn't say what I am saying."

What Kuhn's subject may be trying to express is that the act of coming to see or know a (human) phenomenon differently is not to be taken lightly. To fail or refuse to do so may not signal a disregard for "negative cases," or what Kuhn describes as "considerable resistance to the idea of falsifying evidence." It may just be an assertion that the criteria relevant to supplanting or discarding a view of this sort have not been met. Whereas, for Kuhn, to hold views in this manner is demonstrative of an inability (a cognitive deficit) to make "available for independent examination" one's own view.

For these reasons it is questionable whether Kuhn's data demonstrate that these subjects are closed to the possibility that their views might be wrong. Rather, it may be the criteria of refutation that they reject. Taylor warns us of "the epistemological tradition" that "constantly nudges us towards a mistrust of transition arguments. It wants us to look for "criteria" to decide the issue, i.e., some considerations which could be established even outside the perspectives in dispute and which would nevertheless be decisive" (Taylor, 1989, p. 73). ${ }^{10}$ That the "criteria" that Kuhn uses are limited is supported by her report that only 26 percent of her subjects who did not generate alternative theories offered genuine evidence. This suggests that subjects producing arguments of this sort were less likely to treat their explanations as theories for which alternatives could be generated. More importantly, it suggests that these narratives, or what Aristotle called inductive or paradigm arguments, were not intended to be taken as hypotheses. The question for Kuhn becomes whether her model is guilty of eliminating this type of reasoning simply by fiat. In defending her own account Nancy, another of Kuhn's subjects, makes an explicit appeal to this legitimacy of just this strategy:

[School failure]

Nancy: Well I could give examples of people I heard about that it happened to, and I could ask them questions about what they've seen in their own classes. 
Interviewer: Just to be sure I understand you, can you explain exactly how this would show that this is the cause?

Nancy: Because if I could give examples, they couldn't disprove my examples since they really happened. (Kuhn, 1992, p. 162)

Kuhn attempts to force her own framework by always presuming that there is something further (one's "theory") which these arguments must be intended to support. The only way that Kuhn can account for this reasoning using her framework is to declare that in such cases an error has been made since "it is not only examples that are "proven" simply by their occurrence; it is the theory itself" (Kuhn, 1992 p. 162). But surely this is to just beg the question."

Baron, in his review, addresses this issue by questioning whether Kuhn's subjects might be "answering the wrong question" due to "their inability to understand the interview questions." In dismissing this as a potentially serious problem he concludes that:

Kuhn would argue, I think, that subjects certainly knew what the words mean (especially given the fact that most questions were repeated in different ways), so, if they did not respond appropriately, it was most likely because they did not regard the distinction conveyed by the words to be important. Misunderstanding, if it occurred was therefore very likely a result of the very deficits that Kuhn claims to find. (Baron, 1991, p. 64)

The possibility argued for here is that the misunderstanding occurs as a result of improperly distinguishing the different criteria or modalities of criticism. To challenge whether a theory is wrong, one appeals to the truth of the evidence or the validity of the conclusions drawn from it - in either case, a perfectly legitimate line of questioning. In contrast, in practical or informal arguments, there is (and must be) a limit to what can be called into question Here, the most difficult issue is discerning just what is an acceptable target for criticism, that is, knowing what calls for justification. Indeed, some rhetoricians, such as Perelman, would hold that:

You justify only what can be the object of condemnation or criticism, what can be judged, i.e., an action or agent. ... You do not justify something that need not conform to norms or criteria or achieve some goal. Neither do you justify something that incontestably comes up to your norms or criteria or goals. Justification deals only with what can be or is being debated. Consequently, what is absolutely valid need not submit to the process of justification; and conversely, what you tend to justify cannot be considered unconditionally and absolutely valid. (Perelman, 1989, pp. 9293)

It may be for this reason that many of Kuhn's subjects become angry, obstinate, or resigned when faced with what they perceive is an unwarranted call for justification. We have insisted that in presenting a practical argument often there is no underlying "theory" for which one's narrative constitutes support. What resists criticism, then, is not the possibility that alternate factors might better account for the (general) phenomenon under discussion, but the integrity of the individual's practical knowledge as it applies to the values and choices at issue. To bluntly put into question the latter can legitimately be experienced as a personal attack. What may seem to be wanting is a reason why the practical ends and values by which they have been living should be put 
into question (see Taylor, 1989, p. 73). Take, for example, one of Kuhn's worst case scenarios:

\section{[school failure]}

Interviewer: Suppose now that someone disagreed with your view that this is the cause, what might they say to show that you are wrong.

Marilyn: They will never prove me wrong. I stand firm. I am a parent. I have two children, and they're not going to prove me wrong.

Interviewer: What evidence might this person give to try to show that you were wrong?

Marilyn: I'm not really interested. All I have are the results that I put into it, and its worked thus far, and I'm not changing my stance. And they're not going to prove anything to me, because if they do, to me they're just narrow people who want things just exactly the way they want. It's not going to work out that way.

Interviewer: Could someone prove that you were wrong?

Marilyn: No, they're not going to prove a darn thing to me. This is my career.

Interviewer: Is there any fact or evidence which, if it were true, would show your view to be wrong?

Marilyn: No. I'm a parent. I've lived it. Absolutely. My experiences may not coincide with somebody else's. Maybe their life was a lot easier. So they will be speaking from their experience. But don't step on my turf. (Kuhn, 1992, pp. 166-67)

It remains that Marilyn may not be claiming there is one, and only one, explanation for the problem of school failure but, rather, that there is at least some small part of it to which her own practical insight can contribute. According to this understanding, Marilyn is dogmatically entrenched only as she staunchly refuses to accept the possibility of refutation of that contribution, i.e., to accept that her own practical knowledge of childrearing can somehow be proven wrong or repudiated.

Kuhn, on the other hand, concludes that Marilyn's "theory" is "incontestable" due to a "sense of ownership... that undermines its independent existence" (Kuhn, 1992, p. 167). However, from the fact that subjects become obstinate or combative when faced with what they perceive a challenge to the integrity or relevance of their own practical knowledge, we cannot conclude that they have an aversion to examining the reasons that support their views. Rather, we might suspect whether it is a narrow view of how they come to have and to hold these views that is at fault. What Kuhn may fail to appreciate is that when ordinary people are asked why some important human phenomenon occurs some subjects will choose to speak from (and appeal to) the depths of their own practical knowledge. To expect that this knowledge should be open to "disconfirmation" in the manner of empirical hypotheses is to misunderstand the nature (or grammar) of this form of argument. To insist on it may be to force one's interlocutor into an area they do not wish to go. When this line is crossed, or perceived to be crossed, the practical ends and character of that individual may considered to be 
at issue, and the call for justification may be taken up as the instigation of a quarrel. According to this interpretation we might take Marilyn's stringent objections to be directed at the course of Kuhn's research questions as much as to the possibility that she considers her own argument "incontestable." At any rate, these considerations do not support Baron's interpretation that subjects simply do not regard "the distinction conveyed by [Kuhn's questions] to be important."

It should be emphasized that there is no intention here to suggest that applying one's own practical knowledge and experience constitutes a superior strategy for responding to Kuhn's questions. Kuhn's questions can be addressed adequately using either, or a mixture of both practical and theoretical reasoning. ${ }^{12}$ Nor is there any reason to suppose that a subject's use of a single strategy allows us to assume a lack of competence or interest in the other. The objection is directed, rather, only at treating practical or transition type arguments as failed theoretical explanations (what Kuhn calls pseudoevidence). This said, we might ask if there remains any reason to follow Kuhn in privileging theoretical over practical accounts. After all, Kuhn reports that her most expert subjects (philosophy students) are also more successful reasoners according to her own standards. Should this not be taken as evidence that the better educated, more critical thinkers are also those most able to submit even practical claims to theoretical justification? While this remains very much an open question, we need not accept Kuhn's own conclusion on this matter. It may be the case that these more astute subjects are also more awake to the subtleties of experimental task demands. That is, they may be more able and willing to adjust their responses in line with the reasoning that the course of Kuhn's interview format clearly promotes. Interestingly, there may also be some subjects that are cognizant of both modes of reasoning and yet remain stubbornly committed to accounts that are based on their own practical knowledge and opinion. In such cases, it may be especially inappropriate to apply Kuhn's own standards (see subject $40 \mathrm{Cms}$ below). Consideration of these issues brings us to an examination of Kuhn's claims concerning her subjects' understanding of the nature of their own knowledge and reasoning.

\section{Metacognitive Issues: People's opinions about the nature of their opinions}

Kuhn suggests that the cause of many of her subjects poor performance is their immature epistemological theories. These theories represent the various and often implicit attitudes that subjects hold concerning the general nature of knowledge and beliefs. Kuhn measures her subjects epistemological beliefs using a framework that is based on work by Perry (1970) and others (Kitchener \& Fischer, 1990; King, Kitchener, Davison, Parker, \& Wood, 1983). Epistemic maturity was assessed by asking subjects how their own views would stack up against an expert opinion and then by comparing these responses to the three levels summarized in Table 2. 
Table 2

Epistemological Theories.

\begin{tabular}{|c|c|c|}
\hline Absoutrst & Multipust & Evaluatrve \\
\hline $\begin{array}{c}\text { Knowledge is } \\
\text { objective certain and } \\
\text { simply accumulates. }\end{array}$ & $\begin{array}{c}\text { Knowledge is, } \\
\text { subjective dictated } \\
\text { only by personal } \\
\text { tastes and wishes. }\end{array}$ & $\begin{array}{c}\text { Knowledge is an } \\
\text { open-ended process } \\
\text { of evaluation and } \\
\text { judgment. }\end{array}$ \\
\hline
\end{tabular}

Kuhn reports the distressing finding that $50 \%$ of her sample exhibit absolutist theories of knowledge, $35 \%$ held multiplist epistemic views, and only $15 \%$ treated knowledge claims according to the evaluative model. Kuhn suggests that the extent of this epistemic "naivet " may explain her subjects poor performance since subjects "must see the point or value of argument if they are to engage in it. If one accepts the absolutist view of knowledge as certain and accumulative or the multiplist view as entirely subjective, argument becomes superfluous" (Kuhn, 1992, p. 168).

For example, a number of Kuhn's subjects, when asked if their theories could be proven wrong, responded that while they could envisage evidence or proof against it, this would not necessarily mean that their own opinion is wrong. The complexity of the considerations involving a choice between two practical accounts has already been alluded to. Comparing an expert (theoretical) and a lay-person's (practical) explanation raises additional concerns. Some of these concerns are, I believe, actually voiced by a number of Kuhn's subjects: subjects whom she scores as holding a multiplist view of the nature of knowledge claims. For instance one subject's answer to the question whether someone could prove them wrong was the somewhat puzzling response that "They could prove me wrong if they can give me good examples, but I can still hold to my opinion" (Kuhn, 1992, p. 169). One reasonable interpretation of this response (Kuhn's own I believe) is that if someone thinks that they can be proven wrong and, yet, still hold to their own opinion, they must also believe in the reality of multiple truths formed according to taste, etc. However, recalling Raz's claim concerning the role of incommensurability in practical thought, it also may be the case that these subjects are simply affirming the independent value of their own opinion.

Kuhn's own view of the nature of knowledge is perhaps ambiguous. While she affirms the possibility of different "correct" viewpoints, she also seems to hold that the 
kinds of considerations relevant to choosing between them are commensurate. Kuhn's idea of judgment (in the evaluative sense) rests on the idea that the individual choose between the expert and herself on the basis of evidence for the two different accounts. Hence, while there is room for disagreement about what is the case, the criteria for the adjudication of the disagreement are not in dispute. What I would like to suggest, and what Kuhn may fail to realize, is that many of her subjects refuse to trade their opinions against the promise of solid proof and that they make this judgment precisely to express their support for the value of one's own practical knowledge and opinion. While these symbolic judgments of incommensurability may not resolve all epistemic ambiguities, they do unambiguously affirm the independent worth of one's practical knowledge. Take, for example, the following apparently multiplist argument.

$(40 \mathrm{Cms})$ (Could someone prove that you were wrong?) I suppose intellectually somebody could give me statistics that would show that the position I hold reflects only a minority of reasons why children fail and therefore prove me wrong. But I would probably not change my opinion. It's the result of lifelong personal experience and quite frankly, I think that it is right. I think that it reflects the reality of the situation as I've experienced it. (Kuhn, 1991, p. 182)

Putting aside the obvious difficulty that statistical proof is compatible with exceptions, what is interesting about this response is the subject's ability to reproduce a strategy for theoretical justification and, yet, is reticent to concede that it constitutes an adequate refutation of their practical experience and belief. Again, the claim is not that these subjects believe that the premises of their practical beliefs cannot be subject to challenge, but that they can only be challenged, as it were, from within, i.e., by showing how it is that they could have come to be mistaken about "the reality of the situation as [they] have experienced it" (see Hollis, 1994). To ask whether one's opinion can be proven wrong in the manner of empirical hypotheses may be to misinterpret the framework that informs the reasoning that some of Kuhn's subjects attempt. Consider, again, the following responses:

(TCfc) (Would you be able to prove this person wrong?) No, they couldn't prove it, but they could give a good argument.(Why couldn't they prove it?) Because its my opinion, and it can't be right or wrong. (Kuhn, 1991, p. 181)

(20Cfs) (Would you be able to prove this person wrong?) No, I would just be able to say I disagree with you this is why and you can't tell me that my experience is wrong because this is what my experience was. (Kuhn, 1991, p. 182)

$(60 \mathrm{Cmc})$ (Would you be able to prove this person wrong) I don't think you can prove anybody, really, because everybody has another point of view, and everybody has a right to their point of view. (Kuhn, 1991, p. 183)

Responses such as these may, or may not, signal absolutist or mulitplist epistemologies. The criterion for assessing a theoretical knowledge claim is by appeal to the evidence. The appropriate concerns to be voiced here include considerations such as "Has the theory been tested?" or, "Is it the case that A varies with B in the manner predicted?" The criteria for changing a knowledge claim would include the lack of such support, or a failure to observe the expected associations. On the other hand, included in the grounds for assessing or re-assessing an opinion is that it be tested against one's own practical knowledge and experience. Here considerations such as "How does that sit with you?" can become relevant. Criteria for changing an opin- 


\section{Matthew Wilks Keefer}

ion can include whether the agent would be able or willing to incorporate this knowledge for use in their own (future) practical deliberations and choices, i.e., that they be accepted as plausible reasons for the agent. This is why a change or shift is rarely immediate or completely decisive. A normal (and successful) response here might include something like "Yes, that sounds appealing to me" or, "You may be right, I'll have to see about that," etc. In such cases, the claim that opinions and proofs should not be compared is that they are founded on different grounds, aimed toward different purposes, and evaluated according to different criteria.

These responses suggest that a refusal to compare these two forms of knowledge (or choose between them according to criteria appropriate to one) can itself be understood as a legitimate affirmation of their independent value and intrinsic worth. ${ }^{13}$ In such cases, as Raz puts it, "failure of commensurability is a success" (Raz, 1986, p. 353). We may conclude, then, that rather than disclosing an epistemological "naivet" that precludes the very possibility of argumentative engagement, such refusals can be considered an authentic affirmation of the value of their own contribution to it and, hence, an intrinsic part of its function and purpose.

\section{Summary and Conclusions}

The arguments presented here suggest that practical and theoretical reason constitute distinct domains that can serve divergent interests and purposes. As Taylor notes: practical reasoning is "...the domain where we deliberate about our future actions, assess our own and others' character, feelings, reactions, comportments, and also attempt to understand and explain these." (Taylor, 1989, p. 69). The discursive practices wherein these arguments take place produce a vocabulary that will "constitute the most realistic and insightful for the things of this domain. What these terms pick out will be what to us is real here..."(Taylor, 1989, p. 69). Taylor argues that if we cannot explain human action well without these terms this is because these terms denote real features of the domain of human action. The case has been made that at least part of the function of our informal practices of practical reasoning and argument is to render intelligible the values and goals that constitute just this domain. Their pivotal role in our practical and moral deliberations argues against any wholesale replacement of them with the vocabulary and constructs of the social sciences.

In the sphere of our everyday practical activity, some of the most important beliefs we hold are based on the values and commitments by which we live out our lives. Our interpretation of these values are applied both to the explanation of our own and others actions, and to the justification of why we (and others) act as we do. Where people might express opinions directed at understanding important social phenomenon (like why people go wrong in life, fail at school etc.,) social scientists hold positions for the purposes of testing theories and confirming research hypotheses. When positions and opinions are contested, scientists must appeal to "evidence" while people may rely on their practical knowledge and powers of persuasion. While the two modes may not be mutually exclusive, it is questionable whether one can investigate the latter solely in terms of the theory and methods that define the former, and then draw conclusions pertaining to the general nature of informal reasoning and argument. 
While practical reasoning and argument has no claim to provide the definitive method for explaining human behavior (this can be done using either or both methods) an understanding of our informal accounts of human behavior that ignores practical reason must be incomplete.

I have argued that Deanna Kuhn has not provided us with adequate reasons why our ordinary vocabulary and methods of practical argument ought to be replaced. Given the resistance on behalf of many of her own subjects, who perform so poorly according to her standards, it is questionable whether Kuhn's theory of argumentation can claim to be exhaustive in "defining what it means, cognitively speaking, to be an educated person, or at least what it means to define an educated person as one who thinks well" (Kuhn, 1992, p. 173).

\section{Endnotes}

'I would like to express my gratitude to Keith Stanovitch, Merrilee Salmon, David Olson, James Voss and an anonymous reviewer for helpful comments on earlier drafts of this paper. Send correspondence to: University of Missouri - St Louis, MH 405, 8001 Natural Bridge Rd., St Louis MO 63121 .

${ }^{2}$ The theory need not be rejected of course, as there is remains the possibility that auxilary hypotheses be posited that protect the core (see Lakatos, 1978).

${ }^{3}$ There is, of course, much dispute concerning the nature of causality in recent writings in the philosophy of science. However, for the purposes of our distinction the following description might suffice:

"... [T]he broad idea is that events are governed by laws of nature which apply whenever similar events occur in similar conditions. Science progresses by learning which similarities are the key to which sequences. That catches the familiar dictum that science explains particular events by generalizing and by making them cases of laws at work. To this often (but not always) is added an idea that a cause makes its effect happen, implying perhaps that to find a cause is to show why the effect had to happen." (Hollis \& Smith, 1990, p. 3)

${ }^{4}$ While there may be a certain point in time where, say, a marriage proposal is accepted, there is not, usually, any actual point when one would pronounce the goal or purpose of one's marriage realized. Rather, we are likely to say that our practical knowledge and beliefs help us in participating in basic values and commitments (Grisez, Boyle \& Finnis, 1987). A similiar problem applies to identifying failure or betrayal in our pursuit of significant goals and values. Here, it is not unusual to hear judgments of the sort: "I thought I had a loving marriage but as it has turned out he was never really married at all". Such a "discovery" is likely to require a thorough reevaluation of what Taylor calls the "interpretations of what I have been living" (Taylor, 1989, p. 72).

${ }^{5}$ The importance of nestedness to the evaluation of action is simply that while there are likely to be many subgoals that make up a comprehensive goal, the success or utility of an action should not be judged in terms of the number of goals it helps the agent to reach but, in terms of its contribution to the highest goal it serves (see Raz, 1986, p. 293).

${ }^{6} \mathrm{Raz}$ distinguishes comprehensive goals from long-term goals. His example is having the goal that one should experience a luxury cruise before the age of fifty may qualify as a long-term goal (given the need to save over an extended period) though it is not the kind of goal that would pervade the agent's everyday life plans and projects ( $\mathrm{Raz}, 1986$ ).

'It will be suggested in Part II that some responses that Kuhn describes as signaling a relativist 
epistemology are, in fact, symbolic judgments of incommensurability.

${ }^{8}$ Taylor continues:

We are convinced that a certain view is superior because we have lived a transition which we understand as error-producing and hence as epistemic gain. I see that I was confused about the relation of resentment and love, or I see that there is a depth to love conferred by time, which I was quite insensitive to before. But this doesn't mean that we don't and can't argue. Our conviction that we have grown morally can be challenged by another. It may, after all, be an illusion. And then we argue; and arguing here is contesting between interpretations of what I have been living. (Taylor, 1989, p. 72)

${ }^{9}$ Baron does not tell us what this evidence is, but it may be assumed he is referring to the fact that most of Kuhn's subjects said they were certain the arguments (they just gave) were, in fact, the cause of school failure, etc. I will provide an alternative explanation below for the certainty that many of Kuhn's subjects express.

I"Taylor goes on to argue that "there cannot be such considerations. My perspective is defined by the moral intuitions I have, by what I am morally moved by. If I abstract from this, I become incapable of understanding any moral argument at all. You will only convince me by changing my reading of my life story, of the transitions I have lived through - or perhaps refused to live through" (Taylor, 1989, p. 73).

"The question is precisely whether these arguments should be treated as theories.

${ }^{12}$ Of course, people can and do apply the explanatory models derived social science in their everyday accounts of human behavior and, a complex point, may use these to identify or to perform certain types of actions that correspond with these models. The point is complex, because it "suggests, disconcertingly that whether an account of social action offered by social science is correct may depend partly on whether it is believed" (Hollis, 1994, p. 162). Hollis argues that this marks an important difference in the nature of natural and social scientific explanations.

${ }^{13}$ They also might explain what Kuhn calls the "seeming contradiction" in the (supposed) absolutist view of knowledge where: "Subjects adhere to the belief in certain knowledge, claim high certainty regarding there own theories, and yet profess that other views could be correct"(Kuhn, 1991, p. 176).

\section{References:}

Aristotle, (1992) Aristotle on rhetoric: A theory of civic discourse. Trans. G. Kennedy. New York: Oxford University Press.

Baron, J. (1991) The Skills of Argument by Deanna Kuhn. Book Review in Informal Logic: Vol (XIV.I).

Finnis, J., Boyle, J. \& Grisez, A. (1987) Practical Principles, Moral Truth, and Ultimate Ends: American Journal of Jurisprudence. (32) 99-151.

Harré, R. (1984) Personal Being. Oxford: Oxford University Press.

Hollis, M. (1989) The cunning of reason. Cambridge: Cambridge University Press.

Hollis, M. (1994) The philosophy of social science: An introduction. Cambridge: Cambridge University Press.

Hollis, M., \& Smith, S. (1990) Explaining and understanding international relations. Oxford: Clarendon Press.

Johnston, P. (1989) Wittgenstein and moral philosophy. New York: Routledge.

King, P., Kitchener, K., Davison, M., Parker, P., \& Wood, P. (1983) The justification of belief: in young adults: A longitudinal study. Human Development. (26), 106-116. 
Kitchener, K., \& Fischer, K. (1990) A skill approach to the development of reflective thinking. In D. Kuhn (Ed.) Contributions to human development: Vol. 2I. Developmental perspectives on teaching and learning thinking skills. Basil, Switzerland: Karger.

Kuhn, D. (1992) Thinking as Argument. Harvard Educational Review. Vol. 62 (2), 155-179. Kuhn, D. (1993) Connecting Scientific and Informal Reasoning. Merrill-Palmer Quarterly. Vol. $39(1), 74-103$.

Kuhn, D. (1991) The skills of argument. New York: Cambridge University Press.

Lakatos, I. (1978) The methodology of scientific research programmes. New York: Cambridge University Press.

Maclyntre, A. (1984) After virtue: A study in moral theory. Notre Dame: University of Notre Dame Press.

Milligan, D. (1980) Reasoning and the explanation of actions. Atlantic Highlands NJ: Humanities Press.

Parfit, D. (1984) Persons and reasons. Oxford: Clarendon Press.

Perelman, C. (1980) Justice, law, and argument: Essays on moral and legal reasoning. Hingham MA: D. Reidl Publishing Co.Perelman, C. (1989) The new rhetoric of Chaim Perelman: Statement and response. Lanhan MD: University Press of America.

Perry, W. (1970) Forms of intellectual and ethical development in the college years. New York: Holt, Rinehart \& Winston.

Raz, J. (1986) The morality of freedom. Oxford: Clarendon Press.

Robinson, D. (1985) Philosophy and psychology. Cambridge MA: Harvard University Press.

Taylor, C. (1964) Explanation of behaviour: New York: Humanities Press.

Taylor, C. (1989) Sources of the self: Cambridge: Harvard University Press.

Taylor, C. (1981) Understanding and explanation in the Geisteswissenschaften. In S. Holtzman \& C. Leich (Eds.), Wittgenstein: To follow a rule. Boston: Routledge.

von Wright, G.H. (1971) Explanation and understanding_1 thaca, NY: Cornell University Press. Walton, D. (1990) Practical reasoning: Goal-driven, knowledge-based action-guiding argumentation. Savage MD: Rowman \& Littlefield Publishers Inc.

MATTHEW WILKS KEEFER UNIVERSITY OF MISSOURI - ST LOUIS DEPARTMENT OF BEHAVIORAL STUDIES 8001 NATURAL BRIDGE RD. MH 405

ST. LOUIS, MISSOURI 63121 